\title{
Dynamic Modeling of ALS Systems
}

\author{
Harry Jones \\ NASA Ames Research Center
}

Copyright $@ 2003$ Society of Automotive Engineers, Inc.

\begin{abstract}
The purpose of dynamic modeling and simulation of Advanced Life Support (ALS) systems is to help design them. Static steady state systems analysis provides basic information and is necessary to guide dynamic modeling, but static analysis is not sufficient to design and compare systems. ALS systems must respond to external input variations and internal off-nominal behavior. Buffer sizing, resupply scheduling, failure response, and control system design are aspects of dynamic system design. We develop two dynamic mass flow models and use them in simulations to evaluate systems issues, optimize designs, and make system design trades. One model is of nitrogen leakage in the space station, the other is of a waste processor failure in a regenerative life support system.
\end{abstract}

Most systems analyses are concerned with optimizing the cost/benefit of a system at its nominal steady-state operating point. ALS analysis must go beyond the static steady state to include dynamic system design. All life support systems exhibit behavior that varies over time. ALS systems must respond to equipment operating cycles, repair schedules, and occasional off-nominal behavior or malfunctions. Biological components, such as bioreactors, composters, and food plant growth chambers, usually have operating cycles or other complex time behavior. Buffer sizes, material stocks, and resupply rates determine dynamic system behavior and directly affect system mass and cost. Dynamic simulation is needed to avoid the extremes of costly over-design of buffers and material reserves or system failure due to insufficient buffers and lack of stored material.

\section{INTRODUCTION}

Modeling systems behavior is not merely useful, it is unavoidable. All human projections about the future, reasoning that "If I do this, then that will happen," are based on models of how the world works. Most everyday models are unconscious, qualitative, and influenced by implicit factors. Engineers and scientists are trained to use explicit, quantitative, mathematical models based on data and physical laws to predict how systems will perform.
Most of the systems models that everyone uses are static rather than dynamic. Static models apply when systems are operating continually in their steady state, their external inputs do not vary, and their internal configurations remain unchanged. Static systems analysis is necessary and should always be done before dynamic modeling and simulation. There are several good reasons to use static models. First, static models are much simpler than dynamic models. Many system behaviors and potential problems can be ignored in static analysis. Second, the static steady state performance of a system is its desired product, the reason it is built. Static performance is the most important single aspect of any system, unless it has a dangerous potential for causing harm. The third reason for relying on static models is that the traditional approach to engineering design is to limit the system performance requirements and then over-design the hardware to guarantee the desired steady state performance. Dynamic behavior can be largely suppressed by costly but simple brute force design.

Nonetheless, dynamic modeling and simulation is absolutely necessary. The most casual observation of the real world shows that things change continually and often drastically. Change can not be ignored. A so-called "surprise" occurs whenever the real world does not conform to our mental model of it. If we are not to be disconcerted by changes in the real world, we need to explore dynamic models that include the causes and effects of change.

Two particular aspects of ALS systems engineering, buffer sizing and controls design, stand out as obviously requiring dynamic modeling and simulation. If we have an integrated life support system with each subsystem and component operating constantly at matched steady state rates, no buffering is needed. But if some material flow or processing function is interrupted, the system quickly fails. Spare material and processing capacity is needed but static analysis does not indicate this. The processing rates and buffer size to accommodate intermittent resource inputs and demands, batch processing, down times, etc., can be determined only by dynamic modeling and simulation. The crude approach to system controls is to design a system using static steady analysis, then add 
on some buffering and a control system in an attempt to keep the system at steady state. The correct approach is to design a dynamic system that can operate within the expected changing requirements and varying environment and can compensate for hardware changes, maintenance and repair down times, etc. The system and its controller must be designed and optimized together, using dynamic simulation. The ALS system processors must have off/on capability and variable processing rates (including rates above nominal steady state) to allow the control system to compensate for demand changes, failures and down time.

Most ALS analysis is static. (Drysdale et al. 1993) (Drysdale et al. 1994) (Finn 1998) (Jones 2003) A small portion is dynamic. (Finn 1999) Previous work reviewed the potential for system dynamics and nonlinearities to cause unacceptable performance and damaging instability in ALS systems. (Jones 2001) (Jones 2002) Dynamic modeling is needed. We can not consider processing cycles, processor scheduling, supply and demand variations, transients, statistical variations, interruptions, and failures, without dynamic modeling and simulation. We can not design buffers, controls, or variable rate processors without dynamic modeling and simulation.

\section{SPACE STATION NITROGEN LEAKAGE}

The methodology of dynamic modeling and simulation and its relation to static steady state modeling is demonstrated by a study of nitrogen leakage and resupply. Probably the simplest life support task is providing nitrogen for use as an atmospheric buffer gas. Nitrogen is not consumed, recycled, or generated, it only leaks into space and is resupplied.

\section{STATIC ANALYSIS OF NITROGEN LEAKAGE}

The atmosphere composition at sea level is $21 \%$ oxygen and $79 \%$ nitrogen and the same composition is usual for space missions. If we allow for the leakage of ten space station elements, one equipment airlock cycle per week, and one crew airlock cycle per day, the estimated space station atmosphere leakage is $3.59 \mathrm{~kg}$ per day, including $2.84 \mathrm{~kg}$ of nitrogen. The nitrogen resupply rate must be equal to the leakage rate of $2.84 \mathrm{~kg}$ per day. Once we allow the additional mass needed for resupply tankage, the static steady state analysis of nitrogen resupply is complete. We know the mass of resupply nitrogen for a space station mission of any duration.

Static analysis matches the average use rate to the resupply or regeneration rate. It uses EXCEL or back-ofthe-envelope calculations and is a quick, useful, necessary first step in analysis. But static analysis is not sufficient.

We must consider the resupply timeline in order to size the shuttle and station nitrogen buffer tanks. If we assume a shuttle flight every 90 days, each flight must bring $256 \mathrm{~kg}$ of nitrogen. Adding a 30-day contingency, the total station nitrogen storage needed is $341 \mathrm{~kg}$. (See the Appendix - analysis notes, item [1], for complete details of this analysis.)

\section{NOMINAL DYNAMIC NITROGEN BALANCE}

A Matlab/SIMULINK model was developed that includes the ten element space station nitrogen gas volume, the leakage, the airlock losses, and the nitrogen tanks that are refilled by Shuttle. We initially assumed constant leakage, one equipment airlock cycle per week, and one crew airlock cycle per day with the nitrogen losses above.

The nitrogen leakage and resupply model behavior is shown in figure 1 below.

Nitrogen, kg

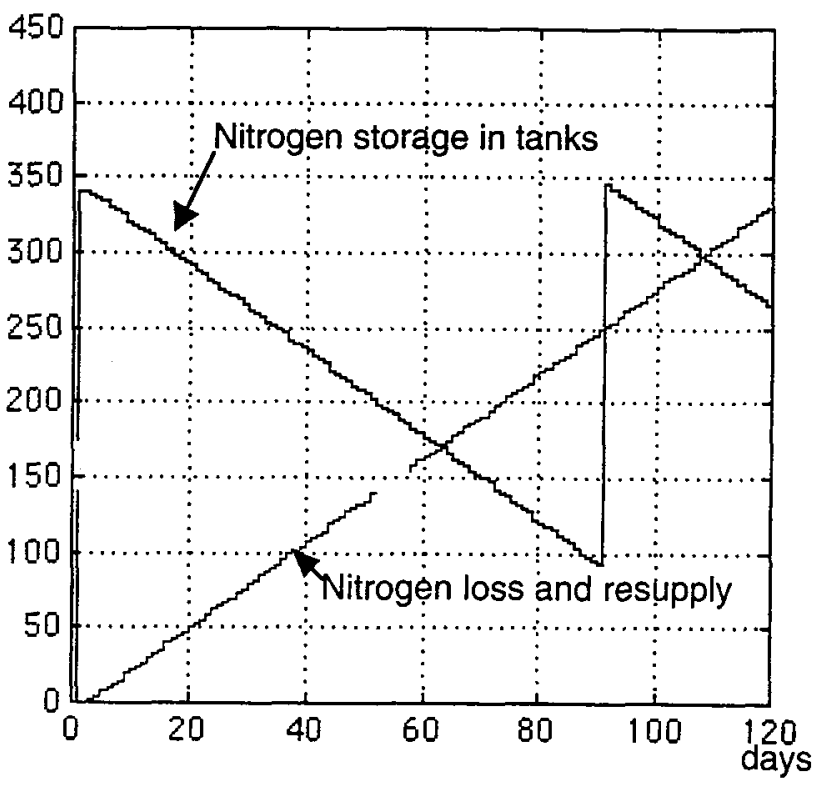

Figure 1. Nitrogen tank storage and resupply with a constant loss rate.

The accumulated nitrogen loss increases at a constant rate from 0 at day 0 to $341 \mathrm{~kg}$ at day 120 . The loss is due to the constant leakage, the daily crew Extra-Vehicular Activity (EVA), and the weekly equipment transfer through the airlock. The nitrogen storage in tanks decreases from $341 \mathrm{~kg}$ at day 0 to $85 \mathrm{~kg}$ at day 90 , when a resupply of $256 \mathrm{~kg}$ from shuttle tanks increases storage to $341 \mathrm{~kg}$ and restores the original station supply. This basic dynamic modeling and simulation defines the resupply tank sizes as well as steady state resupply rate.

\section{OFF-NOMINAL DYNAMIC NITROGEN BALANCE}

Modeling and simulation are even more necessary when we consider the effects and responses to off-nominal 
conditions. Suppose the following failure scenario occurs:

1. A large amount of nitrogen $(98.8 \mathrm{~kg})$ is lost on day 30 due to a failure fully depressurizing one of the ten station elements.

2. After restoring pressure, the leakage rate of the damaged element is found to have increased from $0.18 \%$ to $1.0 \%$, adding $0.81 \mathrm{~kg} /$ day more leakage.

3. The crew EVAs and equipment transfers through the airlock must be maintained.

4. The next nitrogen resupply by shuttle is increased to $400 \mathrm{~kg}$ but must be delayed 10 days to day 100 .

We modify the SIMULINK model to include these offnominal events. The model behavior is shown in figures 2 and 3 below.

Nitrogen, $\mathrm{kg}$

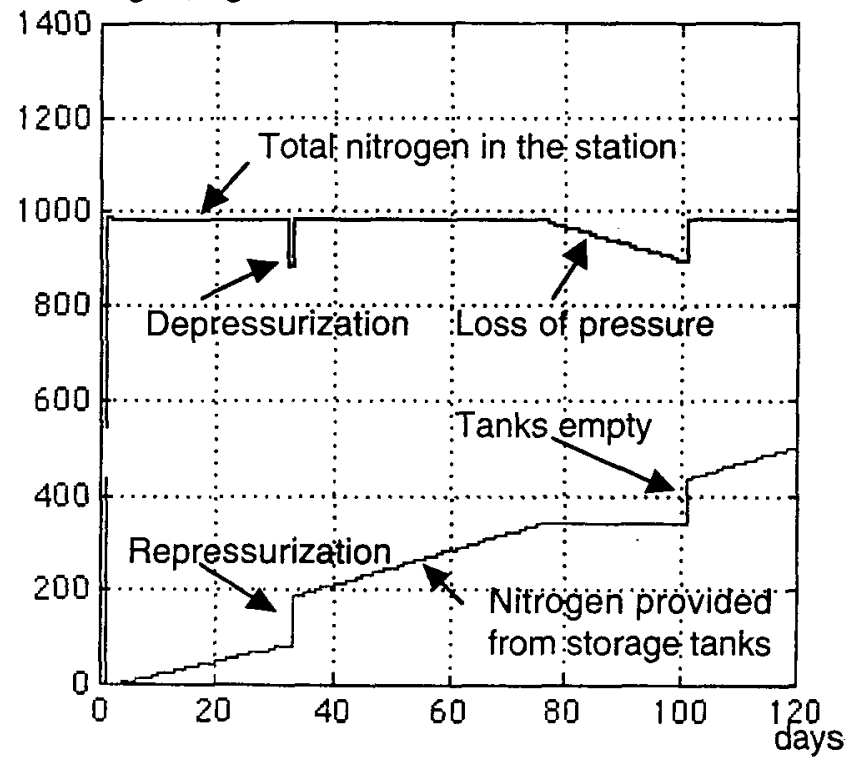

Figure 2. Habitat nitrogen and storage input for offnominal nitrogen loss.

The upper trace in figure 2 shows the total nitrogen in the ten habitable elements of the space station. The total nitrogen is constant at $988 \mathrm{~kg}$ until the element depressurization event on day 30 . The lower trace is the accumulated nitrogen provided to the habitable elements from the storage tanks. The input from storage usually increases at a constant rate but jumps by $98.8 \mathrm{~kg}$ at day 30 to quickly repressurize the damaged element. The storage tanks are all empty at day 75 , so the nitrogen pressure in the habitable elements decreases until it is about $10 \%$ below nominal. At day 100 , the $400 \mathrm{~kg}$ resupply arrives and is used partly to restore habitat pressure and partly left in tanks for future use. Figure 3 below shows the nitrogen storage in the station tanks.

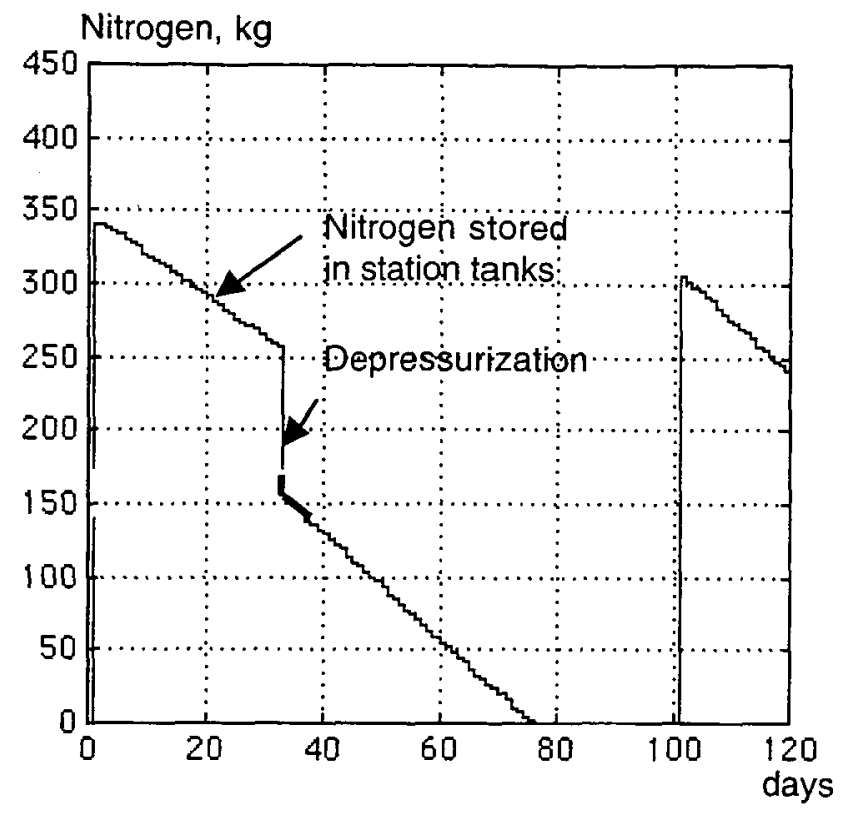

Figure 3. Nitrogen storage in tanks for off-nominal nitrogen loss.

Note that, even though the total resupply brought up in shuttle tanks is $400 \mathrm{~kg}$, about $100 \mathrm{~kg}$ is used immediately to increase habitat pressure. This leaves only about 300 $\mathrm{kg}$ to be stored in station tanks to compensate for leakage and airlock cycling until the next resupply. Do we have enough? Not unless we reduce airlock use. The new off-nominal use rate is $3.65 \mathrm{~kg} /$ day, so $300 \mathrm{~kg}$ lasts only 82 days. We would need $329 \mathrm{~kg}$ for 90 days.

In these examples of nitrogen loss, the oxygen loss is $26.6 \%$ of the nitrogen loss. For the nominal case this is $0.76 \mathrm{~kg} /$ day, and for the off-nominal case it increase to $0.97 \mathrm{~kg} /$ day after the chamber de- and re-pressurization. These numbers are similar to the oxygen consumption per crewmember per day, which averages $0.84 \mathrm{~kg} / \mathrm{day}$ but varies from 0.65 to $1.5 \mathrm{~kg} / \mathrm{day}$. (Reed and Coulter, $p$. 122) (Wieland, p. 6.) The nominal oxygen leakage is equivalent to having an additional crewmember and can not be ignored. Any atmosphere loss will impact the oxygen system.

\section{NITROGEN LEAKAGE SUMMARY}

Static analysis matches the average use and resupply rates. Static analysis is a quick, useful, necessary first step, but it is not enough. Nominal dynamic analysis is needed to define buffers sizes and to plan scheduling or design operational procedures to provide resupply. Additional dynamic analysis is needed to simulate failures and plan responses.

The above space station nitrogen leakage example is very simple. The complexity of a dynamic simulation is determined by the number of interconnected buffers or storage elements. In this nitrogen example we have two 
connected buffers, the station nitrogen storage tanks and the station pressurized volume itself.

Dynamic systems with only one or two storage buffers connected by feedback loops can show complex behavior. Typical advanced life support systems are much more complex. The Matlab/SIMULINK model of a complete bioregenerative system has 30 storage buffers. (Finn 1999) These are crew chamber atmosphere, crew chamber atmosphere leakage, biomass chamber atmosphere, biomass chamber atmosphere leakage, biomass nutrient tank, eight crop trays' biomass, five different crops' storage, inedible biomass storage, oxygen tank, carbon dioxide tank, methane tank, waste carbon store, waste water tank, clean water tank, bioreactor sludge tank, solid waste tank, solid waste chamber atmosphere, solid waste chamber atmosphere leakage, and nitrogenous waste tank. The next example of static analysis followed by dynamic modeling and design is of a simple closed biological life support system with five storage buffers.

\section{WASTE PROCESSOR FAILURE IN A BIOREGENERATIVE SYSTEM}

This analysis was inspired by a very simplified abstract model of an ecological life support system described in an early paper by Babcock, Auslander, and Spear (1984). We investigate the behavior of a fully closed life support system with a waste processor failure. The three processors in the system are the crew, plant growth chamber, and a waste processor. The system has only five types of material flow streams. These are edible biomass or food, inedible biomass or waste, oxygen, carbon dioxide, and water. There are storage tanks for food, inedible plant waste, oxygen, carbon dioxide, and water. Additional biomass, oxygen, and carbon dioxide are contained in the plant and crew chambers.

The original paper of Babcock et al. uses combined material flows. All processors and buffers receive and produce tailored mixed flows of food, waste, oxygen, carbon dioxide, and water. Because the mixed flows contain solid, liquid, and gas, the system hardware design and failure behavior is not intuitive. This reduces the apparent relevance of the simulation results. Here we separate the material flows.

\section{BIOREGENERATIVE SYSTEM DESCRIPTION}

We assume a highly simplified closed regenerative human ecosystem. Its three chemically active processors are plants, humans, and a waste oxidizer. The plants are primary producers, using light energy to combine carbon dioxide and water in order to produce glucose and oxygen. The humans metabolize the glucose using oxygen, converting these inputs to carbon dioxide and water. One producer and one consumer form the simplest possible closed ecological system, but we will assume that the plants produce glucose that is half edible and half in waste biomass. The waste oxidizer converts the inedible glucose to carbon dioxide and water using oxygen. See the system block diagram in figure 4 below.

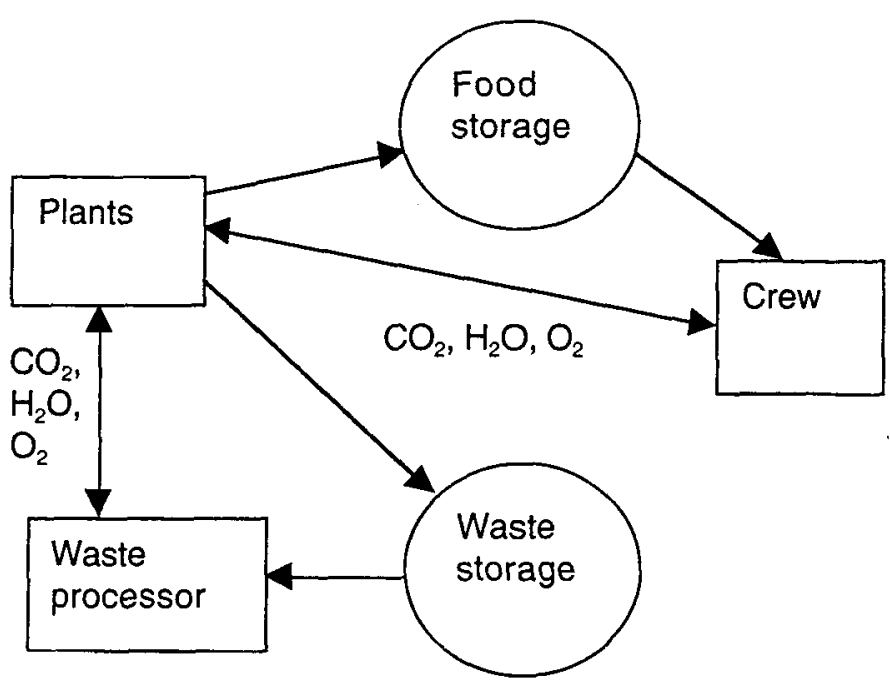

Figure 4. Simple closed ecological life support system

SYSTEM PROCESSOR CHEMICAL EQUATIONS - Plant photosynthesis uses the following chemical reaction:

$6 \mathrm{CO}_{2}+6 \mathrm{H}_{2} \mathrm{O} \rightarrow \mathrm{C}_{6} \mathrm{H}_{12} \mathrm{O}_{6}+6 \mathrm{O}_{2}$

The relative masses can be found using the molecular weights. As the molecular weight of hydrogen is 1 , carbon is 12 , and oxygen is 16 , we have the following total molecular weights:

$264+108 \longrightarrow 180+192=372$

We assume human metabolism is equal to the complete oxidation of glucose. The reaction is:

$\mathrm{C}_{6} \mathrm{H}_{12} \mathrm{O}_{6}+6 \mathrm{O}_{2} \longrightarrow 6 \mathrm{CO}_{2}+6 \mathrm{H}_{2} \mathrm{O}$

This is simply the inverse of photosynthesis. The waste oxidizer produces exactly the same reaction as the humans. Photosynthesis requires input energy, while human metabolism and waste oxidation produce energy.

SYSTEM MATERIAL FLOWS - Some of the oxygen and carbon dioxide are contained in the closed system atmosphere and circulate freely between the three processors, plants, humans, and waste oxidizer. We assume the water produced by human metabolism and waste oxidation enters the atmosphere as water vapor and is condensed and returned to the plants. We ignore other human waste. Large amounts of water are required for drinking, plant growth, and human hygiene. We will assume that these other three water streams are recycled independently and consider only recycling the relatively small amount of water involved in photosynthesis, human metabolism, and waste oxidation. The plants gradually produce first inedible and 
then edible biomass, which we treat as pure glucose. At maturity, the plants are harvested and the edible and inedible biomass is separately stored.

SYSTEM STORAGE BUFFERS - The five materials used, edible biomass or food, inedible biomass or waste, carbon dioxide, oxygen, and water are stored in the system. Inedible and edible biomass are first contained in the plants, then harvested and stored in the food and waste buffers. Carbon dioxide and oxygen are stored largely in tanks, with some in the atmosphere. The human metabolic water is stored in a tank, with drinking, plant, and hygiene water.

PROCESSOR OPERATIONS - We consider the crew, the plants and the waste processor.

Crew - The objective of the closed life support system is to provide the crew with oxygen, water, and food. Any failure to provide the full requirement is a serious problem. Under failure scenarios, the crew could survive with temporarily reduced food. Metabolic water is insignificant compared to drinking, plant, and hygiene water, so it's loss is unlikely to be a critical failure. Oxygen is an urgent need. Maintaining low carbon dioxide levels, less than a few thousand parts per million, is mandatory. (Wieland, p. 184-5)

Plants - We will assume one tray of food plants, all planted at the same time. The plant growth cycle will be something like wheat, with a 60-day growth period and a $50 \%$ harvest index, except that the assumed plant produces only edible and inedible glucose. From day 0 to 20 , the plants exhibit a straight-line increase in photosynthetic rate. On day 20 they establish a full canopy and the maximum photosynthesis and biomass production rate. In the first 20 days they produce $20 \%$ of final biomass, all inedible. From day 21 to 35 , another 30 $\%$ of the final biomass is produced, all inedible. From day 36 to 60 , the last $50 \%$ of biomass is produced, all edible. (Volk et al.) (Jones et al.) The assumed plant photosynthetic rate over time is shown in figure 5 below.

\section{photosynthesis rate}

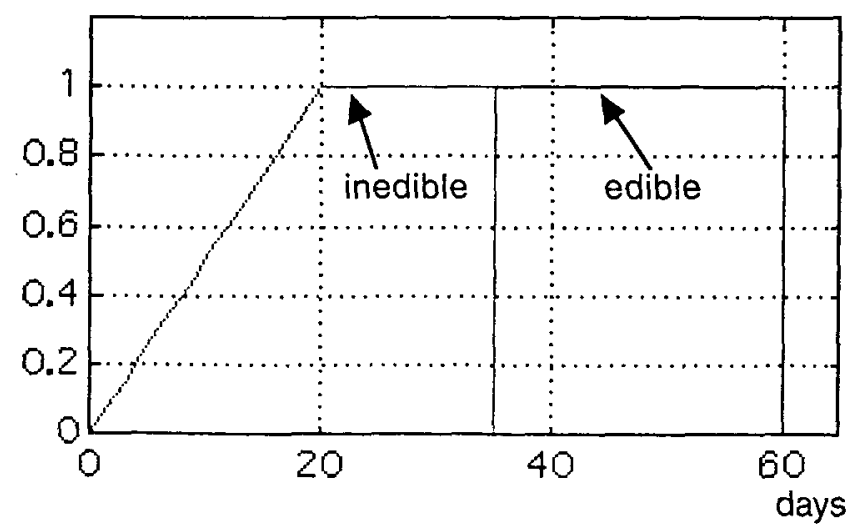

The average photosynthetic rate over the 60 days shown in figure 5 is $5 / 6$ of the peak rate. Later we consider the effect of a waste processor failure and reduced carbon dioxide on plant growth. The total plant growth is limited to the amount possible using the carbon dioxide available in the atmosphere. Metabolic water is assumed always available. Plant growth may be affected by light energy and other factors. If the amount of inedible biomass, the light collecting canopy, is reduced due to some problem in the first 35 days, the subsequent production of edible biomass is reduced proportionately to the loss in inedible biomass.

Waste processor - The waste oxidizer is needed to convert waste biomass into carbon dioxide for the plants. If it were not available, waste biomass would accumulate, and ultimately all carbon would be sequestered in waste. We assume an incinerator that performs a daily burn designed to maintain a fixed buffer level of carbon dioxide. Because of the large buffer of atmospheric oxygen, the oxygen needed for waste processing is always available. The waste processor controller monitors the stored carbon dioxide. It requests and burns waste daily when the plants are strongly photosynthesizing. The produced carbon dioxide is stored and released gradually to avoid excessive atmospheric carbon dioxide levels.

SYSTEM PERFORMANCE ISSUES - Can this closed system survive temporary failures of the waste processor? This will depend on the storage capacities, the amount and distribution of initial material in the system, and the failure recovery strategy. How exactly do the initial storage sizing and the material allowances affect the system survivability? What is the least costly way to reduce the harm of potential failures? Do control algorithms provide a low cost approach to increasing survivability?

\section{INITIAL STATIC SYSTEM DESIGN}

Before we can simulate dynamic behavior, we must design the system in more detail. As is usual, the initial mass flow will be based on static steady state systems analysis. Then we investigate the nominal dynamics to size the storages and then add a waste processor control designed to maintain the system at steady state.

SYSTEM FLOW SIZING - The system flow rates are shown in moles in Table 1 below. The rates are determined by the system processor chemical equations above. Negative numbers indicate the processor outputs, and positive the inputs. By using moles flow per day, we can check the mass balance easily.

Figure 5. Plant photosynthetic rate over time. 
Table 1. Average processor input and output flows (moles/day)

\begin{tabular}{|l|r|r|r|}
\hline $\begin{array}{c}\text { lprocessors } \\
\text { flowsl }\end{array}$ & plants & crew & $\begin{array}{c}\text { waste } \\
\text { processor }\end{array}$ \\
\hline edible biomass & -90 & +90 & \\
\hline inedible biomass & -90 & & +90 \\
\hline oxygen & -192 & +96 & +96 \\
\hline carbon dioxide & +264 & -132 & -132 \\
\hline water & +108 & -54 & -54 \\
\hline
\end{tabular}

The edible and inedible biomass flow rates are the average rates over the 60-day plant growth cycle. Referring to figure 5, we see that the average edible and inedible biomass production rates are $25 / 60=5 / 12$ of the peak biomass production rate.

As a real world mass reference point, a material flow of one mole per day scales to about eight grams per crewmember per day. The standard crewmember daily metabolic inputs and outputs include $0.84 \mathrm{~kg}$ of oxygen and $1.00 \mathrm{~kg}$ of carbon dioxide per day. (Wieland, p. 6) (Reed and Coulter, p. 122) If $0.84 \mathrm{~kg}$ of oxygen corresponds to 96 moles, we have 8.8 grams per mole. If $1.00 \mathrm{~kg}$ of carbon dioxide corresponds to 132 moles, we have 7.6 grams per mole. The correspondence is not exact because this simplified model ignores the details of human metabolism.

\section{NOMINAL DYNAMIC ANALYSIS}

We next consider buffer sizing for the steady state, for start up, and over the plant growth cycle.

STORAGE SIZING - To size the system storages, we must consider the system operational modes. We investigate average steady state operation, the initial startup, and system shut down and restart.

For the average steady state operation, we assume constant photosynthesis at $5 / 6$ the peak rate. The oxygen, carbon dioxide, and metabolic water flows of the plants are exactly balanced by the crew and waste processor. Oxygen and carbon dioxide are continually exchanged through the crew and plant chamber atmosphere. No storage is needed. The water produced by crew metabolism and waste oxidation is condensed and added to the plant hydroponics solution. No additional water storage is needed. Unlike the continuous exchange of gases and water, the harvest of solid material is a discrete event. At harvest, the plants produce 60 days food. This is 60 days " 90 moles per day per crewmember $=5,400$ moles per crewmember. This must be stored. An equal amount of waste biomass is produced and stored at the same time. After harvest, the crew and waste processor draw down the stocks of food and waste continuously over the next 60 days.
The initial start up, still assuming the average steady state, requires that 60 days food and 60 days waste be provided in storage. We do not need to provide 60 days oxygen to metabolize the food or oxidize the waste, as the plants will continually provide the oxygen needed. Since it is unlikely that waste will be provided initially, we consider supplying the waste processor products of carbon dioxide and water for plant input. There are two problems. The mass of carbon dioxide and water is more than double the mass of waste they replace, because of the additional oxygen they contain. Half of the oxygen produced by the plants will not be needed for waste processing and must be perpetually stored. It is more efficient to simply fill the food and waste storage at initial start up, just as if we were at the end of a harvest cycle.

This means that we can shut down the system immediately after a harvest and remove the crew, and then return the crew and restart the system at some indefinite later date. Average steady state operation, including initial start up, shut down, and restart requires only the storage of 60 days food and 60 days waste. Steady state analysis indicates that we need storage buffers only for the edible and inedible biomass, each of 5,400 moles.

BUFFERING OVER THE PLANT GROWTH CYCLE - We also consider the buffering needed to compensate for the variation of photosynthesis over the crop cycle. Because photosynthesis increases only gradually after planting, there is an initial low level of plant production of oxygen and plant use of carbon dioxide and water. This transient must be smoothed by buffering. We supply stored oxygen to the crew and store the crew-produced carbon dioxide and water. Later in the plant growth cycle, the plants use more than the average amount of carbon dioxide and water and produce more than the average oxygen, so the buffers can be returned to their initial condition. The amount of buffering is reduced because waste processing is scheduled only when the plants ae at peak photosynthesis, producing more oxygen and requiring more carbon dioxide than the crew can match.

The plants will be producing oxygen and using carbon dioxide and water at the maximum rate after 20 days, after a uniform increase in photosynthetic rate from day 0 . See figure 5 above. The average photosynthetic rate is $5 / 6$ of the maximum rate, and is achieved in $5 / 6$ of 20 days, at day 16.7. The plants reach one-half the average photosynthetic rate at day 8.3. This means that the plants are able to supply all the crew oxygen and to use all the crew produced carbon dioxide and metabolic water. After day 8.3 the oxygen, carbon dioxide, and water buffers gradually return to their initial levels. Before day 8.3 the plants do not produce enough oxygen for the crew and do not use all the carbon dioxide and metabolic water produced by the crew. The net excess of carbon dioxide and water, and the deficit of oxygen, are half of 8.3 days average crew use, or 548 moles of carbon dioxide, 224 moles of water, and 398 moles of 
oxygen. The excess carbon dioxide and water must be stored for later use and the currently needed oxygen must be provided from storage. The required minimum buffer sizes and initially stored amounts are shown in moles in Table 2 below.

Table 2. Minimum buffer sizes and initial materials (moles)

\begin{tabular}{|l|r|r|}
\hline & $\begin{array}{l}\text { buffer } \\
\text { size }\end{array}$ & $\begin{array}{l}\text { initial } \\
\text { stock }\end{array}$ \\
\hline edible biomass & 5,400 & 5,400 \\
\hline inedible biomass & 5,400 & 5,400 \\
\hline oxygen & 398 & 398 \\
\hline carbon dioxide & 548 & 0 \\
\hline water & 224 & 0 \\
\hline
\end{tabular}

On harvest day, 10,800 moles of plant biomass are transferred to storage. This is equal to the initial supply of biomass. Including the oxygen and the initial biomass, the system working material mass is 11,198 moles. (See the Appendix - analysis notes, item [2], for a discussion of staggered planting.)

PRACTICAL BUFFER SIZING - An operational system needs something more than the minimum storage capacity and initial material in order to buffer random fluctuations and to provide some reserve for down time. Oxygen and carbon dioxide are contained in the crew and plant chambers, but the required oxygen and carbon dioxide buffers of Table 2 are large compared to the atmospheric gas content. (See the Appendix - analysis riote [3], for the oxygen and carbon dioxide in the atmosphere.)

We can not eliminate the oxygen and carbon dioxide buffers and use the atmosphere as a buffer. Instead, it would be reasonable to provide larger buffers containing an initial stock of ten day's oxygen and ten days carbon dioxide. Referring to the use rates in Table 1 , this is 1,920 moles of oxygen and 2,640 moles of carbon dioxide. Since 548 moles of carbon dioxide will accumulate during initial startup, we increase the buffer size by this much, to $2,640+548=3,188$.

Water circulates in the drinking, crew hygiene, and plant hydroponics systems. The daily flow of drinking and hygiene water is roughly thirty times the crew metabolic water flow. (See the Appendix - analysis note [4], for a discussion of drinking and hygiene water.) The required mass of plant hydroponics water is equivalent to more than a hundred years plant metabolic use. (See the Appendix - analysis note [5], for a discussion of plant chamber water.)

Because of the large amount of drinking, hygiene, and hydroponics water, storing and buffering human metabolic water is not a problem. In the simulations, we use a large buffer size of 20,000 moles and an initial stock of 10,000 moles, so that no shortages or overflows occur.

However, to correctly estimate the cost of the life support system, we count only the water stock and buffer size needed for life support. The metabolic water is similar to carbon dioxide, produced by the crew and waste processor and used by the plants. We need a buffer containing an initial stock of ten day's metabolic water, 1,080 moles. Since 224 moles of metabolic water will accumulate during initial startup, we increase the buffer size by this much, to $1,080+224=1,304$ moles.

If we provide an additional ten days edible and inedible biomass, the amounts increase from $60^{*} 90=5,400$ to $70 * 90=6,300$ moles. The practical buffer sizes and initially stored amounts are shown in moles in Table 3 below.

Table 3. Practical buffer sizes and initial material(moles)

\begin{tabular}{|l|c|c|}
\hline & $\begin{array}{c}\text { buffer } \\
\text { size }\end{array}$ & $\begin{array}{c}\text { initial } \\
\text { stock }\end{array}$ \\
\hline edible biomass & 6,300 & 6,300 \\
\hline inedible biomass & 6,300 & 6,300 \\
\hline oxygen & 1,920 & 1,920 \\
\hline carbon dioxide & 3,188 & 2,640 \\
\hline water & 1,304 & 1,080 \\
\hline
\end{tabular}

The total system buffer size is 19,012 moles and the system working material mass is 18,240 moles. These amounts will be used below to estimate system cost.

SYSTEM BEHAVIOR AND CONTROL - We consider the behavior and control of the crew, plants, waste processor and chamber atmosphere.

Crew - We assume the crew receives an input of 90 moles of edible glucose and 96 moles of oxygen per crewmember per day, as in Table 1. Each crewmember produces 132 moles of carbon dioxide and 54 moles of metabolic water. If the edible input is reduced, we assume the same use of oxygen and production of carbon dioxide and water, made possible by metabolizing body tissue.

Plants - The plants convert carbon dioxide and water to glucose and oxygen, as in Table 1. All plants will be harvested and replanted every 60 days. If the plants are damaged or destroyed due to some system failure, they may be replanted as soon as the failure is repaired.

Waste processor - Like the crew, the waste oxidizer converts glucose and oxygen to carbon dioxide and water, as in Table 1. The waste processor controller monitors the carbon dioxide stored in the buffer. It 
requests and burns some amount of waste daily when the carbon dioxide buffer is at less than the initial 2,640 moles.

Atmosphere - The flows of oxygen and carbon dioxide are large compared to the amounts stored in reasonably sized crew and plant chambers. We do not have the large atmosphere buffers sometimes envisioned in ecological life support. The system operation requires processors that remove oxygen or carbon dioxide from the atmosphere and store them in buffers.

\section{NOMINAL DYNAMIC SIMULATION}

The dynamic behavior of the closed system under nominal conditions is shown in figure 6 below.

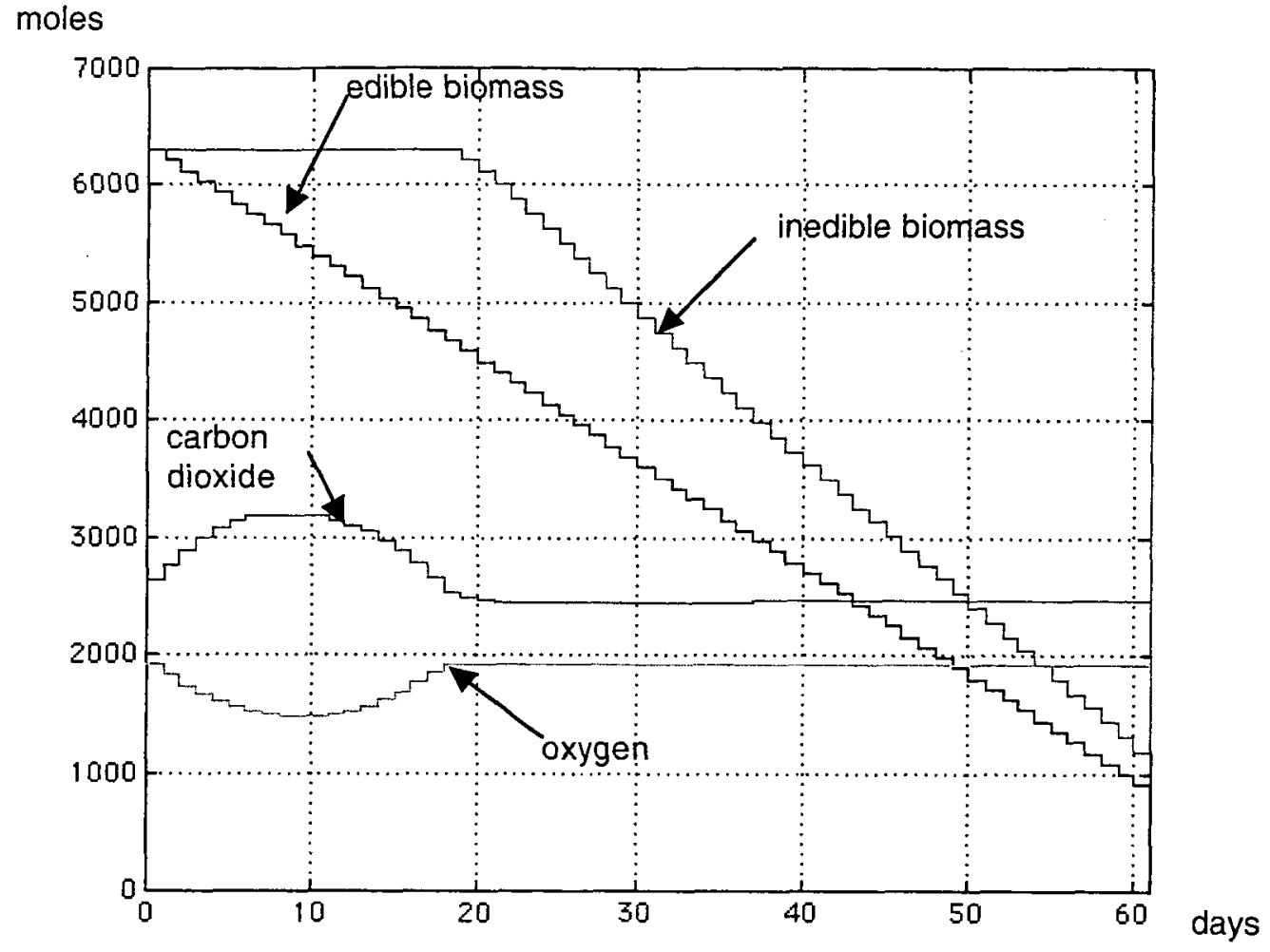

Figure 6. Initial design, nominal operation.

The edible biomass decreases in a straight line from 6,300 moles to 900 moles as the crew consumes it. The inedible biomass remains constant at 6,300 moles until day 19 and then decreases in a straight line to about 1,100 moles as the waste processor burns it to produce carbon dioxide and water. The edible and inedible biomass both return to their initial values after harvest on day 61 . The carbon dioxide increases from 2,640 moles to 3,188 moles on day 7 , as the crew produces more than the plants use, then decreases to the set level of 2,640 moles on day 21 . The oxygen decreases from 1,920 moles to 1,522 moles on day 8 as the crew produces more than the plants use, then increases back to 1,920 on day 18 . The metabolic water, not shown, behaves similarly to the carbon dioxide.

\section{SIMULATION OF A WASTE PROCESSOR FAILURE}

A 14-DAY FAILURE - Assume that the waste processor is inoperative for some period. The purpose of the waste processor is to produce half of the carbon dioxide used by the plants. If the waste processor fails, we may not be able to maintain the target storage level of carbon dioxide. This will not affect plant growth unless the storage becomes completely empty. The initial supply of carbon dioxide of ten days' average plant use, supplemented by the crew production of half of the average plant use, will last 14.3 days during peak photosynthesis. (Appendix - analysis note [6])

The waste processor is not needed at all before peak photosynthesis. After initial planting, the crew produces excess carbon dioxide that lasts until near canopy closure, as shown in figure 6 . Instead of producing more carbon dioxide, we must remove much of the crewproduced carbon dioxide from the atmosphere and store it during the first 21 days.

Suppose we have a fourteen-day waste processor failure beginning sometime after day 21 and ending before day 60 . The carbon dioxide in the buffer will last just until the 
waste processor is repaired. Then the waste processor controller automatically burns enough waste to return the carbon dioxide storage to its normal level. The plants and the edible and inedible harvest they produce are not affected. But there is a significant problem. While the waste processor was inoperative, the plants continued to produce the oxygen that the waste processor normally uses. Since the oxygen buffer was already full with the initial stock, there is nowhere to store the oxygen the plants produce. It all must be vented and lost. After the waste processor is repaired, most of the initial oxygen store is used to burn waste and replenish the carbon dioxide storage. During the beginning of the next planting cycle, when the plants are not producing much oxygen, there is no stored oxygen to support the crew.

The behavior of the closed system with a waste processor failure on day 31 lasting until day 44 is shown in figure 7 below.

moles

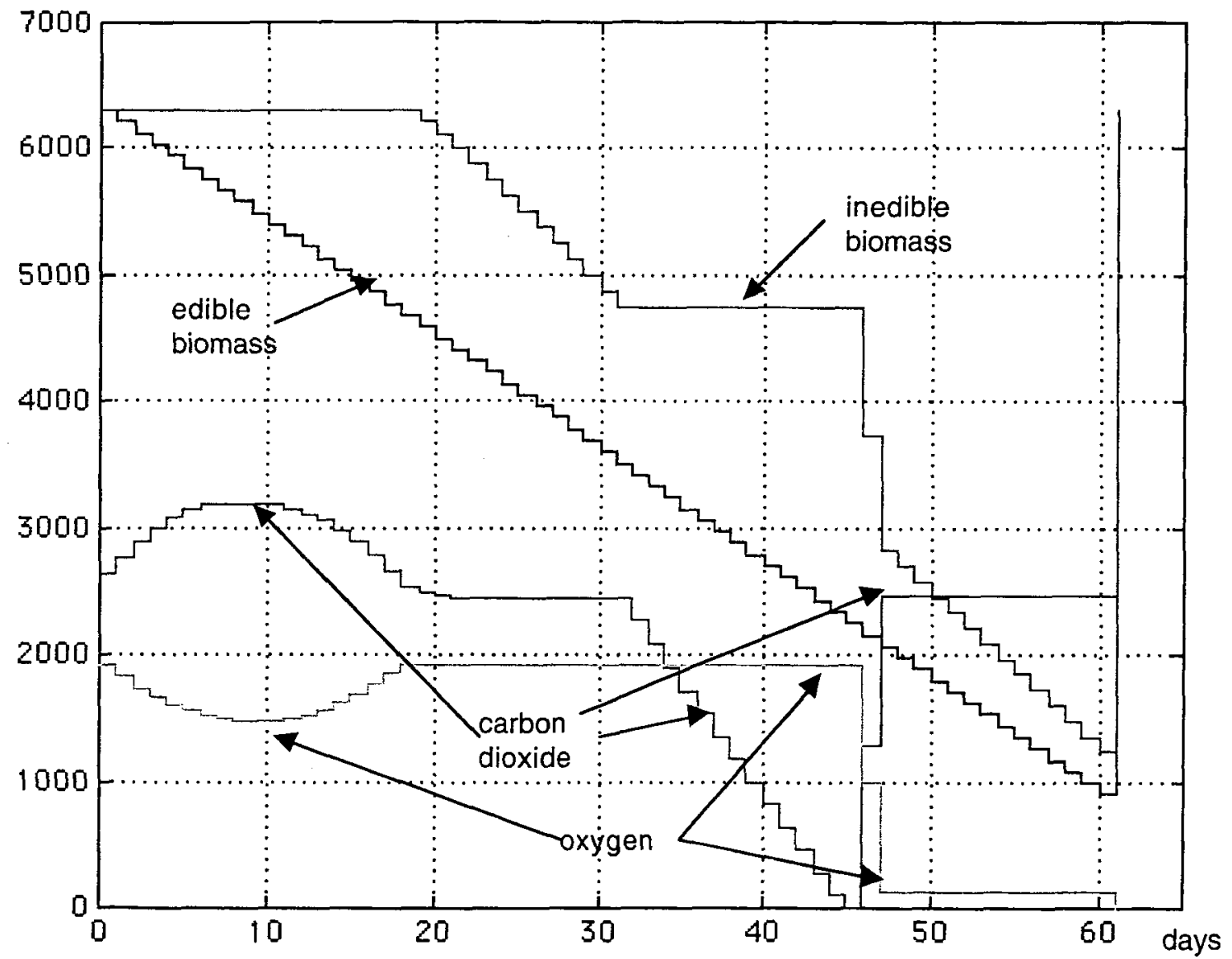

Figure 7. Initial design, waste processor failure on day 30 repaired on day 44 .

From day 31 to 44 , the carbon dioxide store decreases to zero while the inedible biomass store remains constant. After day 44, carbon dioxide is restored to its previous level while the waste storage is reduced to the usual amount for that day. (Appendix - analysis note [7]) Oxygen is reduced to a low level. On day 61, just after the plants are harvested, the stored oxygen drops to zero.

A second failure of fourteen days or less does not have any additional harmful effect. After the first failure, the oxygen buffer has enough spare capacity to accommodate all the oxygen produced when the waste processor is inoperative.

There are several things we can do to increase the system tolerance to a waste processor failure. We could increase the oxygen buffer size so it could hold the oxygen produced by the plants that is not used during the initial failure. We could stop waste processing if it would not leave enough stored oxygen to support the crew after harvest and replanting. We consider failure mitigation after further failure analysis.

FAILURE EFFECT ANALYSIS - Rather than simulating more example failures, we systematically review waste processor failure effects. We consider the impact of waste processor failures on the initial system buffer design of Table 3 above. The impact of a waste processor failure depends on when during the plant growth cycle it occurs and on how long it lasts.

If a waste processor failure occurs during the first 21 days of a plant growth cycle, it has no effect. Over this period, 
the plants do not require more carbon dioxide than the crew produces. Excess carbon dioxide is first stored and later released. No waste processing is needed.

If a waste processor failure occurs on any day from 22 to 60 , the required waste oxidation can not occur. No waste and oxygen are used by the waste processor and no carbon dioxide and water are produced. The waste buffer remains at its current level. More than half (the waste processing share) of the plant-produced oxygen is lost, because the oxygen buffer is already full. The carbon dioxide and water storages are drawn down to support plant growth.

The effect of the failure depends on how long it lasts. Just as the carbon dioxide buffer can go 14 days after a waste processor failure before emptying, the oxygen buffer has enough oxygen to provide the equivalent of 14 days waste processing after the waste processor is repaired. However, in order to have enough stored oxygen for the crew during the next planting, we need to retain 2.1 days of the average plant oxygen production. A waste processor failure of more than 11 days will use up too much stored oxygen to replace the carbon dioxide when the waste processor is repaired. (Appendix - analysis note [8])

If the failure lasts 11 days or less, the system will retain enough stored oxygen to continue operation. After the waste processor returns on line, oxidizing the waste needed to restore the carbon dioxide storage to its initial level, enough oxygen remains to support the crew while the plants are small. If the failure lasts more than 11 days and we restore the carbon dioxide storage to its initial level, there will not be sufficient stored oxygen for the crew during the next planting. The crew can survive by using oxygen in the crew and plant chambers, but this is still a serious life support failure. Waste processing should not use the oxygen that the crew needs to begin the next planting period.

If the waste processor failure of less than 11 days continues through harvest on day 60 , a second effect occurs in addition to depletion of the oxygen storage. Some inedible biomass of the previous harvest was not oxidized, so the new harvest causes the inedible buffer to overflow. The inedible amount lost corresponds to the oxygen lost, since waste and oxygen are the paired unused waste processor inputs. The full buffer obviously has enough waste to provide carbon dioxide in future plant cycles, and there is also just enough to fully maintain the carbon dioxide storage.

If the waste processor failure lasts more than 14 days before harvest on day 60 , the carbon dioxide buffer becomes fully depleted. There is insufficient carbon dioxide for plant growth. Since we use the stored carbon dioxide only after day 21 , carbon dioxide depletion at 14 days later can occur only after day 35 of the plant growth cycle. Only the edible biomass growing after day 35 is reduced. The crew supplies $1 / 2$ of the average carbon dioxide needed by the plants, and $(1 / 2)^{*}(5 / 6)=5 / 12$ of the amount needed during peak photosynthesis. The daily production of edible material is $5 / 12$ of that expected. After the next harvest, the amount of edible material in the buffer is reduced. Also, inedible waste is lost in a two step process. After 14 days, when the waste processor is repaired, there is more waste available than we need to oxidize to refill the carbon dioxide buffer. Then at the next harvest, the inedible buffer overflows. The mass of missing edible biomass has been lost in the form of inedible biomass. If the waste processor failure was long, both edible and inedible buffers will empty during the next planting cycle. In the following cycle, plant production will equalize the stored amounts of edible and inedible biomass. The amounts of both may be inadequate. In general, a material loss will not impair performance if the required steady state buffer materials, shown in Table 2, can be maintained.

A subsequent failure will not cause further harm unless it has a longer duration than any earlier failure. Suppose there is an initial waste processor failure of 11 days duration or less. When the waste processor is repaired, we refill the carbon dioxide buffer and partly empty the oxygen buffer. During any shorter subsequent failure, all the unused oxygen can now be stored in the largely empty oxygen buffer. The oxygen lost during the first failure is temporarily replaced, then used when the waste processor becomes operative. After a second shorter failure is repaired, the carbon dioxide and oxygen buffers return to exactly the same state they had just after the first failure. The same is true no matter how often a failure of the same or shorter duration is repeated. Additional oxygen will be lost only when the second failure is longer than the first. In general, a failure has no permanent effect if the system buffers return to their previous state.

\section{SYSTEM REDESIGN}

FAILURE EFFECT MITIGATION - There are two ways to reduce the impact of a waste processor failure, by redesigning the hardware or by changing the system operations, including controls and procedures. The failure effects described above are of two general types. A buffer may overflow, with the excess material being lost. In the above example, the oxygen buffer is generally full, and a waste processor failure results in plant-produced oxygen being lost. A buffer may empty and not provide a required material flow, impacting a down-stream processor. In the simulated system, a long duration waste processor failure results in the carbon dioxide buffer emptying, reducing plant growth.

Buffer overflows can be prevented by increasing the buffer size. If the buffers are large enough to store all the system material in any possible form, no buffer overflow can occur. Suppose that all buffers in the example system are made large. It is possible that, in the absence 
of a crew, the plants could convert all carbon dioxide into edible and inedible biomass and oxygen. Without plants, the crew and waste processor could convert all the initial store of food and waste material into carbon dioxide and water.

Buffer emptying can be prevented by increasing the initial amount of stored material. To survive permanent failures of the waste processor and plants, the system must contain enough food and oxygen to support the crew for the entire mission. Then the life support is a completely open loop system.

Increasing the buffer sizes and the initial storage amounts can improve failure tolerance, but can also significantly increase the system and mission cost. Increasing the buffers and stored material must be done before the mission during the initial design.

After the mission is underway, we can react to failures only by changing the system operation, perhaps by reprogramming automatic control systems. In the above example, if a waste processor failure is causing oxygen to be lost, we can extend system survival by not allowing the oxygen buffer to be emptied after the failure is repaired. We can reduce the impact of failure by managing the processor operations, material flows, and storage levels. This provides low cost failure mitigation, but the operational options are limited by the initial design configuration.

REDESIGN OBJECTIVES AND APPROACH - The redesign objective is to lengthen the time that the system can support the crew after a waste processor failure. In normal conditions, the waste processor is operated once a day while the plants are at peak photosynthesis. We assume that the waste processor has some small probability of failure every time it is to be operated, and that each day after it fails there is a significant probability that it will be repaired. This means that longer failures have lower probability. Increasing the time the life support system can survive a waste processor failure will improve the probability of crew survival.

The performance metric we use is the duration of the longest repeated waste processor failure that the system can survive. Often shorter repeated failures will have no additional impact, as is the case with the initial system design above. However, some failure repairs are onetime patches, so we also consider the longest single failure that the system can survive.

To optimize a system design, we must consider cost as well as benefit. A direct approach to increasing the survivable failure duration is to increase the buffers and initial storage. This has a significant cost. The cost of the initial stored material can be estimated as proportional to its total mass in moles. Similarly, the cost of the buffers can also be estimated as proportional to the buffer mass, which is proportional to the maximum mass they can contain. Gas tanks typically have a mass roughly equal to the maximum mass they can contain. (BVAD, p. 29) Water tanks may have mass of one-fifth their maximum water content. We assume the edible and inedible biomass (food and waste) is stable and can be stored in bulk, so that the biomass storage buffers require a mass of only one-tenth their maximum biomass content. Using the buffer sizes and initial stocks of Table 3, the cost of the initial design system is 24,869 in mole mass units. (Appendix - analysis note [9])

Redesign 1: Increasing material buffers and initial stocks We can survive a waste processor failure lasting nearly one full plant growth cycle if we increase buffers and storage sufficiently. We increase the initial storage to include all the carbon dioxide that the waste processor would produce over a plant growth cycle and provide empty storage for all the oxygen that the waste processor would have consumed. This is half the carbon dioxide that the plants consume and half the oxygen they produce over one plant growth cycle. (Appendix analysis note [10]) This system works well if the waste processor is repaired so that the waste buffer can be emptied (to restore the carbon dioxide level) before the next harvest. If not, the new waste biomass harvest overflows its buffer. This can be prevented by adding enough empty capacity to store a full inedible harvest. Now the system can survive a waste processor failure, beginning before the plants reach full canopy (when the plants first require carbon dioxide to be produced by waste processing), and extending until after the plants are harvested. This includes 40 days of planned waste processor use and up to another 20 days during initial planting when the waste processor is not needed. The cost of this system is 41,761 in mole mass units, a 68 percent increase. Because the carbon dioxide buffer is refilled after each waste processor failure and repair, this system can survive repeated long duration waste processor failures.

Redesign 2: Controlling oxygen level - We investigate a second redesign. Changing the waste processor control can extend failure survival duration several days at no cost. We halt operation of the waste processor if the stored oxygen is less than twice the amount needed to support the crew during initial planting. The system now can survive repeated fourteen-day failures of the waste processor that empty the carbon dioxide buffer. Longer failures can be tolerated, but the lack of stored carbon dioxide after the fourteenth day of full canopy plant growth (day 35 of the plant cycle in figure 5) reduces the production of edible biomass. The crew supplies some carbon dioxide to the plants, but if the failure exceeds twenty-one days, the harvest plus the excess initial extra store of ten days food will run out before the next harvest. (Appendix - analysis note [11]) 
Redesign 3: Controlling oxygen level and adding food To extend the system survival, we increase the initial excess food storage by the amount lost if the waste processor fails throughout the planting cycle. We set the total initial food storage to 95 days. (Appendix - analysis note [12]) The system behavior is shown in figure 8 below.

moles

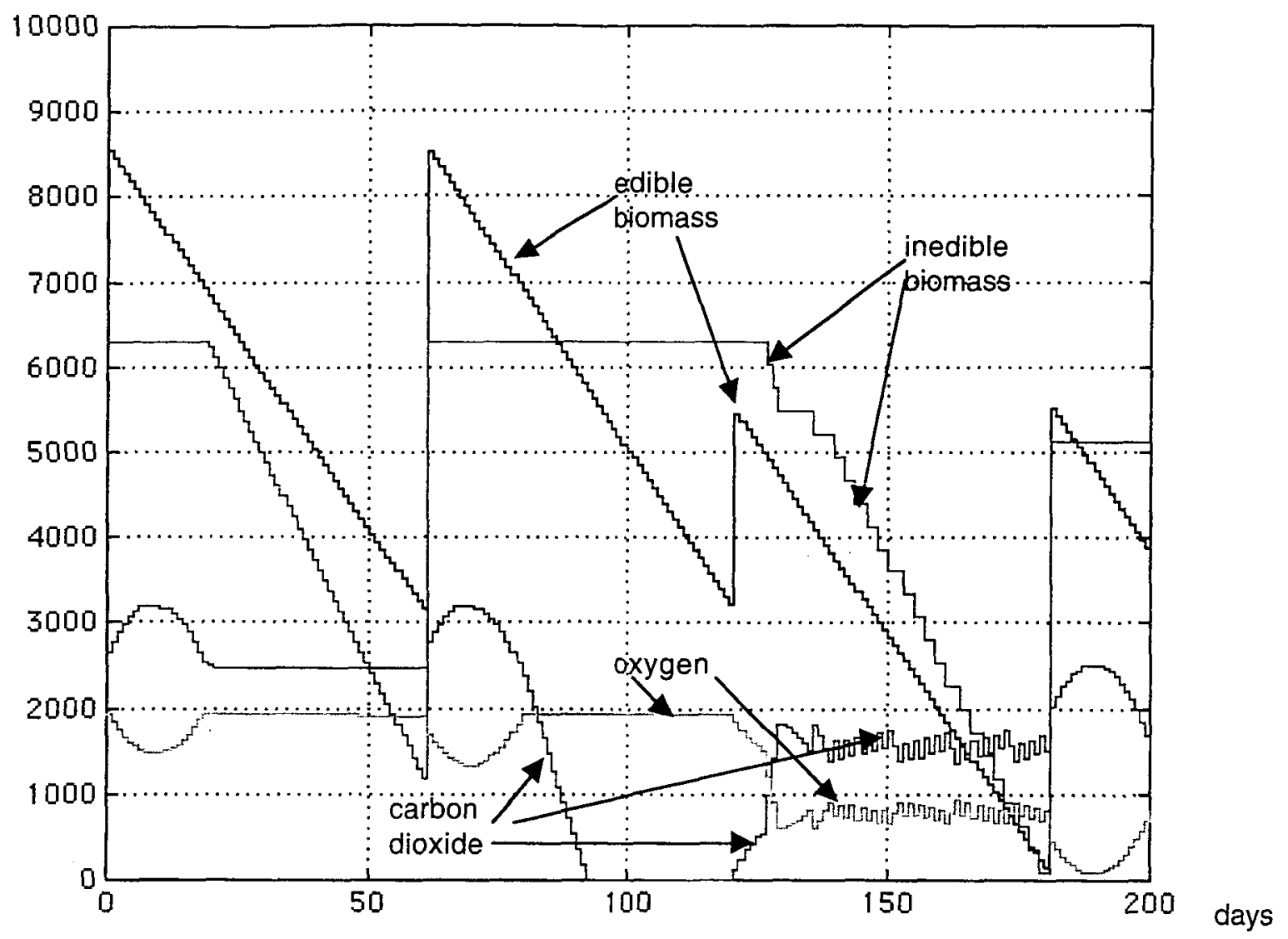

Figure 8. Redesign 3 with oxygen use control and added food

Harvest and replanting occur on day 60 . The waste processor fails on day 75 and is repaired on day 125 , a 50-day failure duration. The carbon dioxide storage empties on day 89 and subsequent edible biomass growth is reduced. At the harvest on day 120 , the edible buffer is only partially refilled, but - because of the higher initial amount of food - the food lasts until the next harvest on day 180. As the inedible buffer size was not increased, waste biomass overflows on day 120 and is lost. After the waste processor is repaired on day 125 , the oxygen is reduced, but not to less than about 800 moles, and the waste is oxidized and the carbon dioxide is increased as far as this allows. The oscillations of the carbon dioxide and oxygen levels show the action of the waste processor controller. The system with control of oxygen use and added food survives a waste processor failure lasting throughout an entire plant growth cycle, up to 60 days. A 60-day failure beginning at any time can be survived.
The cost of this system is 27,244 in mole mass units, only a 10 percent cost increase from the initial system. This cost increase is much less than the 66 percent cost increase of the redesign 1 above, which used a larger initial carbon dioxide store and larger oxygen and waste buffers. This system is not as robust as the redesign 1 because it can not survive a second 60-day failure. The first 60-day failure uses all of the added 35 days initial food storage.

Redesign 4: Dynamic redesign - Rather than treating the failure symptoms of the initial design, we attempt a direct dynamic design. We want the system to survive repeated long duration waste processor failures. The critical product of the waste processor is the carbon dioxide used to support plant growth. We design the waste processor controller and the carbon dioxide buffer to always store all the carbon dioxide needed for one full plant growth cycle. Then as long as the waste processor is available for a few days between harvest and when stored carbon dioxide is next needed, the system can maintain carbon dioxide flow and plant growth. 
At system start-up, we initially supply enough carbon dioxide for a full plant growth cycle, allowing for the half supplied by crew metabolism. We maintain this level by operating the waste processor whenever possible. The carbon dioxide buffer must hold this much plus the initial extra amount generated by the crew while the plants are small. The edible buffer and initial store are reduced to the minimum 60 day supply. We make the inedible buffer the same size but store no initial waste material, as we have the initial carbon dioxide it would produce. We supply twice the oxygen that the crew needs during initial planting. The oxygen buffer must also be able to contain the half of the oxygen that the plants produce over a plant growth cycle, which is normally used by the waste processor. Appendix - analysis note [13])

The waste processor must replace the carbon dioxide storage between harvest, when inedible biomass becomes available, and peak photosynthesis on day 21 , when stored carbon dioxide is needed. Any failure duration of less than 21 days is survivable. The system survives repeated 21-day waste processor failures. The cost of this system is 31,641 in mole mass units, a 27 percent cost increase from the initial system.
Redesign 5: Extended dynamic redesign - If we want the system to survive any 60-day waste processor failure, we need to also fill the inedible buffer at start up. Then the waste processor continually oxidizes this waste to keep the carbon dioxide buffer full. Whenever the waste processor fails, we have 60 days carbon dioxide on hand. We already have the capacity to store the oxygen not used by the waste processor. But if the waste processor fails and is not repaired before the next harvest, the new waste biomass overflows the buffer. We therefor add additional storage capacity for a second inedible harvest. This is essentially the same as redesign 1 above, which increased buffers and storage, with all spare buffer capacity and material removed. The cost of this system is 37,581 in mole mass units, a 51 percent cost increase from the initial system.

\section{DESIGN COMPARISON}

All the above designs perform perfectly under nominal conditions. They respond differently to waste processor failures. The number and duration of waste processor failures they can survive and their costs in mole mass units are compared in Table 4 below.

Table 4. Performance and cost of the different system designs

\begin{tabular}{|l|c|c|c|l|}
\hline Redesign number & $\begin{array}{c}\text { Survivable } \\
\text { failure } \\
\text { duration } \\
\text { (days) }\end{array}$ & $\begin{array}{c}\text { Survivable } \\
\text { number of } \\
\text { failures }\end{array}$ & $\begin{array}{c}\text { Cost } \\
\text { (moles) }\end{array}$ & $\begin{array}{c}\text { Relative } \\
\text { cost }\end{array}$ \\
\hline 0. Initial system design & 11 & many & 24,869 & 1.00 \\
\hline 1. Increase buffers and initial stocks & 60 & many & 41,761 & 1.68 \\
\hline 2. Control oxygen level & 14,21 & $\begin{array}{c}\text { many 14 day } \\
\text { one } 21 \text { day }\end{array}$ & 24,869 & 1.00 \\
\hline 3. Control oxygen level and add food & 14,60 & $\begin{array}{c}\text { many } 14 \text { day } \\
\text { one } 60 \text { day }\end{array}$ & 27,344 & 1.10 \\
\hline 4. Dynamic redesign & 21 & many & 31,641 & 1.27 \\
\hline 5. Extended dynamic redesign & 60 & many & 37,581 & 1.51 \\
\hline
\end{tabular}

Initial design 0 . In the initial system design, a waste processor failure interrupts the production of carbon dioxide and causes the plant-produced oxygen to overflow its buffer and be lost. When the waste processor is repaired, its controller attempts to restore the carbon dioxide buffer level. If the waste processor failure has been longer than 11 days, insufficient oxygen remains to support the crew after the next harvest and replanting, when the plants are producing little oxygen. After the system survives an initial 11 day failure, shorter subsequent failures do not cause additional harm, as unused oxygen can be stored in a largely empty buffer.

Redesign 1 - We redesign the system to increase the duration of failures it can withstand. We increase the buffer sizes and initial storage to provide: 1, all the carbon dioxide that the waste processor would produce over a plant growth cycle, 2, empty storage for all the oxygen that the waste processor would consume, and, 3 , enough empty capacity to store a second full inedible harvest. If the waste processor fails on the first day that it is required during the plant cycle, there is sufficient carbon dioxide in storage to complete the cycle. No harm results unless the waste processor is still unavailable 60 days later, at the same point in the next cycle. The improved performance is obtained at a cost that is 66 percent higher than that of the initial design.

Redesign 2 - As an alternate redesign, we control the minimum oxygen level so there is always enough to support the crew after the next planting. The system can survive repeated fourteen-day failures. The initial store of 
food was 70 days, 10 more than needed for the start up plant cycle. The 10 days use is 7 days production, which allows a single failure of 21 days. This change does not increase the buffer size, material storage, or system cost over the initial design.

Redesign 3 - We can extend the one-time failure survival duration by increasing the initial excess food storage. The crew carbon dioxide output and the carbon dioxide storage are sufficient to grow the inedible plant structure and some of the food, so we need to add only 35 days food to the 60 days start up food. If the waste processor fails on the first day it is required during the plant cycle, the system survives unless the waste processor is still unavailable 60 days later, at the same point in the next cycle. The cost of this system is only 10 percent more than the initial system.

Redesign 4 - In the dynamic redesign, we initially supply enough carbon dioxide for a full plant growth cycle. In subsequent plant cycles, the waste processor must oxidize the inedible biomass after harvest but before stored carbon dioxide is needed, a window of 21 days. We also shrink the biomass buffer sizes to 60 days each and eliminate the initial stored inedible biomass. This system costs 27 percent more than the initial system.

Redesign 5 - The extended dynamic redesign fills the inedible buffer at start up, so the carbon dioxide buffer can be continually filled by waste processing. The system now survives repeated 60-day failures occurring anytime in the plant growth cycle. Redesign 5 is similar to redesign 1 , except that unnecessary storage capacity and material have been removed, reducing the cost increase over the initial system to 51 percent.

Figure 9 below indicates the relative cost versus the repeatedly survivable failure duration for the initial design and the five redesigns.

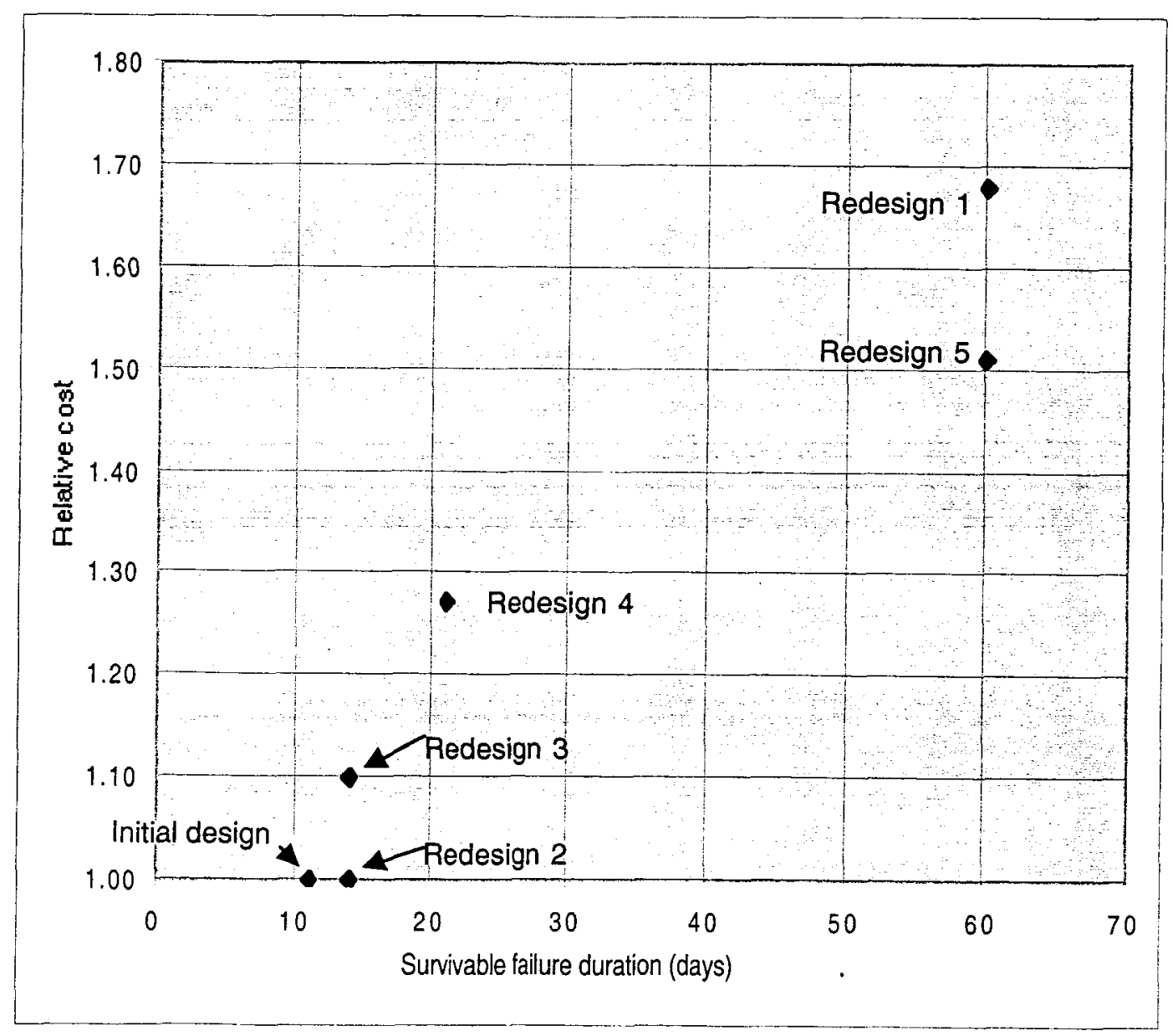

Figure 9. Relative cost versus survivable failure duration 
The initial design can survive repeated waste processor failures of eleven days or less. Redesign 1 survives repeated 60-day failures but requires a 68 percent cost increase for increased materials and buffer sizes. Redesign 2 extends the failure duration of the initial design from 11 to 14 days by limiting the oxygen buffer use, adding no cost. Redesign 3 adds stored food for a 10 percent cost increase in order to survive a single 60 day failure. Redesign 4 survives repeated 21 -day failures at a 27 percent cost increase. Redesign 5 is similar to redesign 1 , surviving repeated 60 -day failures, but has lower 51 percent cost due to minimizing the buffers and stocks.

The cost versus survivability behavior in figure 9 is reasonable, showing higher system cost for better failure performance. The initial design was not specifically intended to survive waste processor failures, but the inclusion of contingency reserves of ten days' materials allowed eleven days survival. Simulating and analyzing the effects of an extended waste processor failure allowed system redesigns to increase failure survival, either by increasing buffers and materials (redesign 1) or by changing the system operational response (redesign improvements in survivability at lower cost increases (redesigns 3 and 4). Striping out the unneeded buffer capacity and contingency reserves minimizes the cost for the specific performance needed (redesigns 4 and 5).

\section{CONCLUSION}

The design approach followed in the nitrogen leakage and bioregenerative system examples is typical of actual practice. System designers nearly always start with a static steady state design. They add controls to keep the system at its static design point if they expect input fluctuations or internal variations. They provide some reasonable padding and safety factors. At this point, systems are sometimes built, tested, and shipped. However, systems subject to input fluctuations, requirements changes, aging, or failures, systems with high costs for buffering and contingency handling, and systems with complex internal controls need more. They should be modeled, dynamically simulated, and designed to cope with plausible departures from the nominal steady state. Dynamic simulation and design is necessary for systems that must handle internal and external changes.

This point has been made before.

"Initial design studies for closed life support systems concentrate on the equilibrium requirements for supporting the crew. These studies give some indication of mass and volume requirements by specifying the flows that will be necessary through various processors, and thus give some indication of the minimum unit size. However, the life support system must be capable of maintaining vital functions during temporary failures of some of its components. Extra storage must be provided, processors must have the capability of operating above (or below) their equilibrium flows, and total amounts of flowing masses in the system must be specified. This part of the design can only be done by considering the system's dynamic behavior as none of these parameters enter into the static equilibrium calculation." (Babcock et al.)

System modeling and dynamic simulation is needed to study important aspects of advanced life support systems, including mass closure, finite storage tank sizes, limited processing rates, and response to offnominal events. Failures or storage losses and overflows can interfere with the desired steady state operation of the closed system. There are several ways to mitigate such off-nominal conditions. The rates of the processors can be increased, made variable, or made more reliable by using parallel or redundant units. The capacities of the storage tanks can be increased. More material can be added in various forms. The operations strategy and control algorithm can be designed to cope with potential events. Modeling and simulation can define the costbenefit of these design strategies.

\section{REFERENCES}

1. Babcock, P. S., D. M. Auslander and R. C. Spear, "Dynamic Considerations for Control of Closed Life Support Systems," Advances in Space Research, vol. 4, pp. 263-270, 1984.

2. BVAD, Advanced Life Support Systems Modeling and Analysis Project Baseline Values and Assumptions Document, A.J. Hanford, JSC 47804, May 2002.

3. Doll, S., and P. Eckart, "Environmental Control and Life Support Systems (ECLSS)," in W. K. Larson, and L. K. Pranke, eds., Human Spaceflight: Mission Analysis and Design, McGraw-Hill, New York, no date, 2000.

4. Drysdale, A., J. Sager, W. Wheeler, R. Forston, and $P$. Chetirkin, "CELSS Engineering Parameters," SAE Technical Paper 93130, 23rd International Conference, 1993.

5. Drysdale, A., M. McRoberts, J. Sager, and R. Wheeler, "Object-oriented Model-driven Control," Advances in Space Research, vol. 14, no. 11, pp. 313-322, 1994.

6. Finn, Cory K., "Dynamic System Modeling of Regenerative Life Support Systems," ICES 199901-2040, Proceedings of the29th International Conference on Environmental Systems, 1999.

7. Finn, Cory K., "Steady-State System Mass Balance for the BIO-Plex," SAE Technical Paper No. 981747, Proceedings of the28th International Conference on Environmental Systems, 1998.

8. Jones, H. W., "Design Rules for Space Life Support Systems," SAE Technical Paper No. 2003-01-2356, Proceedings of the 33rd International Conference on Environmental Systems, 2003. 
9. Jones, H. W., "Survey of Modeling Failures, Dynamics, and Nonlinearities in Advanced Life Support Systems," ICES 2001-01-2302, Proceedings of the 31st International Conference on Environmental Systems, 2001.

10. Jones, H. W., "Nonlinear Dynamic Models in Advanced Life Support," ICES 2002-01-2291, Proceedings of the 32nd International Conference on Environmental Systems, 2002.

11. Jones, H. W., and J. Cavazzoni, "Top-Level Crop Models for Advanced Life Support Analysis," Proceedings of the 30th International Conference on Environmental Systems, ICES 2000-01-2261, July 2000.

12. Reed, R. D., and G. R. Coulter, "Physiology of Spaceflight," in W. K. Larson, and L. K. Pranke, eds., Human Spaceflight: Mission Analysis and Design, McGraw-Hill, New York, no date, 2000.

13. Volk, T., Bugbee, B., and Wheeler, R.M., "An Approach to Crop Modeling with the Energy Cascade," Life Support and Biosphere Science, Vol. 1, pp. 119-127, 1995.

14. Wieland, P. O., Designing for Human Presence in Space: An Introduction to Environmental Control and Life Support Systems, NASA Reference Publication RP-1324, 1994.

\section{CONTACT}

Harry Jones, Ph.D.

Mail Stop 239-8

NASA Ames Research Center

Moffett Field, CA 94035-1000

Phone: 650-604-5518

e-mail: Harry.W.Jones@nasa.gov

\section{ACRONYMS}

ALS: Advanced Life Support

EVA: Extra-Vehicular Activity

\section{APPENDIX - ANALYSIS NOTES}

1. Nitrogen leakage static analysis details - The atmosphere for Space Shuttle, Spacelab, International Space Station, and many Russian missions is sea-level Earth normal. This is 14.7 psi total pressure with about $21 \%$ oxygen and $79 \%$ nitrogen. (Reed and Coulter, p. 105) (Wieland, p. 184)

The leakage design parameter for the original Space Station Freedom was $0.23 \mathrm{~kg} / \mathrm{element}$ per day. A typical laboratory or habitation element had volume of $106 \mathrm{~m}^{3}$. (Wieland, p. 213.) $106 \mathrm{~m}^{3}$ of air at 1 atmosphere pressure and 25 degrees Centigrade corresponds to about 125 $\mathrm{kg}$ of air per element. The leakage rate is then $0.18 \%$ per day. If we assume space station will have ten similar elements, the total loss is $2.3 \mathrm{~kg}$ per day.
The Space Station Freedom equipment airlock had volume of $26 \mathrm{~m}^{3}$ and the crew airlock had a volume of 7 $\mathrm{m}^{3}$. Each was expected to lose a nominal $10 \%$ of the air for each use, with loss up to $100 \%$. (Wieland, p. 213) 2.6 $\mathrm{m}^{3}$ of air at one atmosphere pressure and 25 degrees Centigrade corresponds to about $3.1 \mathrm{~kg}$ of air. The equipment airlock was to be cycled about once per week, so the equipment airlock air loss is $0.44 \mathrm{~kg}$ per day. $0.7 \mathrm{~m}^{3}$ of air at 1 atmosphere pressure and 25 degrees Centigrade corresponds to about $0.85 \mathrm{~kg}$ of air. If the crew airlock is cycled about once per day, the crew airlock air loss is $0.85 \mathrm{~kg}$ per day.

Adding up the atmosphere losses including the ten elements' leakage, one equipment airlock cycle per week, and one crew airlock cycle per day, we have an average atmosphere loss of $3.59 \mathrm{~kg}$ per day. Of this, $79 \%$ or $2.84 \mathrm{~kg}$ is nitrogen.

To date spacecraft have used stored air or pure nitrogen to provide make-up gas. Initial space station designs considered cryogenic storage, which has a lower packaging factor than pressure tanks, but handling difficulties and boil-off losses eliminated this option. The early space station will use stored nitrogen and oxygen, but later space station will recycle oxygen (Doll and Eckart, p. 555) We consider only nitrogen leakage and resupply.

Equating the average nitrogen loss to the resupply rate, we must provide $2.84 \mathrm{~kg}$ per day. If we have a Space Shuttle flight every 90 days, each flight must carry $256 \mathrm{~kg}$ of nitrogen. If we require a 30 day contingency supply, the total nitrogen storage capacity must be $341 \mathrm{~kg}$. These calculations are summarized in Table A-1 below.

Table A-1. Nominal storages and leakage rates.

\begin{tabular}{|l|r|r|}
\hline & \multicolumn{1}{|c|}{$\begin{array}{c}\text { Atmosphere } \\
\mathrm{kg}\end{array}$} & $\begin{array}{c}\text { Nitrogen, } \mathrm{kg} \\
(79 \%)\end{array}$ \\
\hline Ten element capacity & 1,250 & 988 \\
\hline Ten element leakage & $2.3 /$ day & $1.82 /$ day \\
\hline Equip. airlock leakage & $0.44 /$ day & $0.35 /$ day \\
\hline Crew airlock leakage & $0.85 /$ day & $0.67 /$ day \\
\hline 90 day resupply & 323 & 256 \\
\hline 120 day storage & 431 & 341 \\
\hline
\end{tabular}

2. We consider staggered planting. The amount of buffering within the plant growth cycle can be reduced by having several staggered plantings, such as two plantings at days 1 and 31, or three at days 1, 21, and 41 . In the limit, we could have daily harvesting and planting and no buffering at all of food, waste, oxygen, carbon dioxide, or water. But this is less attractive because of the remaining need for initial start up buffering. We still require an initial 60-day supply of food and waste for start 
up. And we require twice as large oxygen, carbon dioxide, and water buffers than in the single planting case, because of the larger delay in reaching the average plant photosynthesis due to continuous planting. We require twice the initial amount of oxygen. (The need is to buffer 17.5 days supplies, since we reach one-half of the average photosynthesis only on day 35 , not day 16.7 as for a single planting.) Another difficulty is that without automatic harvesting and storage, we can not shut down and restart without another 60-day supply of food and waste.

3. We consider how much oxygen and carbon dioxide is in the crew and plant chamber atmosphere. We assume that the atmosphere is sea-level Earth normal. This is 14.7 psi total pressure with about $79 \%$ nitrogen, $21 \%$ oxygen, and $0.04 \%$ carbon dioxide. (Reed and Coulter, p. 105) A typical laboratory or habitation element for the original Space Station Freedom had volume of $106 \mathrm{~m}^{3}$. (Wieland, p. 213.) $106 \mathrm{~m}^{3}$ is 106,000 liters and contains about 4,730 moles of gas. Two habitation elements contain 9,460 moles of atmosphere, 1,987 moles of oxygen, and only 3.8 moles of carbon dioxide. Referring to the use rates in Table 1, this is 20 days oxygen for the crew and 40 minutes carbon dioxide for the plants. If we stored one day's carbon dioxide in two habitats, we would have 264 moles in 9,460 moles, or $2.7 \%$ carbon dioxide. This is too high. (Reed and Coulter, p. 109)

4. How does the amount of drinking and hygiene water compare to the metabolic water? Table A-2 below lists the nominal drinking and hygiene water requirements estimated for Space Station Freedom. (Wieland, pp. 6, 230) (Reed and Coulter, p. 125)

Table A-2: Drinking and hygiene water $(\mathrm{kg}$ per crewmember per day)

\begin{tabular}{|l|r|}
\hline drinking & 1.62 \\
\hline shower & 2.73 \\
\hline dishwash & 5.45 \\
\hline handwash & 4.09 \\
\hline urine flush & 0.50 \\
\hline clothes wash & 12.50 \\
\hline total & 26.89 \\
\hline
\end{tabular}

Water has 18 grams per mole, so the daily non-metabolic water flow per crewmember is 1,494 moles, about 28 times larger than the 54 moles daily metabolic water flow per crewmember. A ten day initial stock of non-metabolic water would be 14,940 moles.
5. How does the amount of plant hydroponics water compare to the metabolic water? A wheat hydroponics system typically requires 130 grams of water (18 grams per mole) for each gram of edible dry biomass ( 180 grams per mole if glucose) produced. (BVAD, p. 38) This means that 1,300 moles of water are required for each mole of edible harvest. Since our edible biomass harvest is 5,400 moles, the hydroponics system uses 5,400 moles edible biomass 1,300 moles water per mole edible biomass $=7,020,000$ moles of water. This is a permanent storage, not the hydroponics flow, but it corresponds to 178 years of plant metabolic water use.

6. The initial supply of carbon dioxide is ten days' average use, but the crew also provides half of the average plant carbon dioxide use. The peak use rate is $6 / 5$ of the average rate. (10 days average use)/(6/5 average use $-1 / 2$ average use $)=10 /(6 / 5-1 / 2)=100 / 7=$ 14.3 days. The initial storage supplemented by the crew production will last 14.3 days during peak photosynthesis.

7. The waste processing restores waste storage to the nominal level over two days because the processing rate per day is limited. In the simulation, the maximum waste processing rate per day is set at the total rate for 11 average days or 9 peak rate days.

8. The oxygen buffer has enough oxygen to provide the equivalent of 14 days waste processing. The reasoning is the same as that for the carbon dioxide loss in analysis note [6]. The oxygen buffer contains ten days average crew and waste processor use. The waste processor and the crew each consume half the average oxygen production. During peak plant photosynthesis, oxygen is produced at $6 / 5$ the average rate. The $6 / 5 \quad-1 / 2$ that would have been used by the waste processor is lost by buffer overflow. The initial storage is $10 /(6 / 5-1 / 2)=14.3$ days peak waste processor oxygen use. However, we need to have enough stored oxygen for the crew during the next planting. Before day 8.3, the plants do not produce enough oxygen for the crew. The net deficit of oxygen is half of 8.3 days average crew use. Half of 8.3 days average crew use is 2.1 days of the average plant production. The length of waste processor failure we can tolerate is equal to the amount of oxygen we can lose divided by the loss rate. $(10-2.1) /(6 / 5-1 / 2)=11.3$ days. If the waste processor failure is less than 11 days, we have enough oxygen, after restoring the initial carbon dioxide, to support the crew after harvest and replanting.

9. The buffer sizes and initial stocks of the initial design are given in Table 3 in the main body. The cost of the initial design system is computed in mole mass units in table A-3 below. 
Table A-3. System cost factors and initial system cost (moles)

\begin{tabular}{|l|r|r|r|r|r|r|}
\hline & \multicolumn{1}{|c|}{$\begin{array}{c}\text { buffer } \\
\text { size }\end{array}$} & \multicolumn{1}{|c|}{$\begin{array}{c}\text { initial } \\
\text { stock }\end{array}$} & $\begin{array}{c}\text { buffer } \\
\text { cost } \\
\text { factors }\end{array}$ & \multicolumn{1}{|c|}{$\begin{array}{c}\text { stock } \\
\text { cost } \\
\text { factors }\end{array}$} & $\begin{array}{c}\text { buffer } \\
\text { cost }\end{array}$ & \multicolumn{1}{c|}{$\begin{array}{c}\text { stock } \\
\text { cost }\end{array}$} \\
\hline edible biomass & 6,300 & 6,300 & 0.1 & 1 & 630 & 6,300 \\
\hline inedible biomass & 6,300 & 6,300 & 0.1 & 1 & 630 & 6,300 \\
\hline oxygen & 1,920 & 1,920 & 1 & 1 & 1,920 & 1,920 \\
\hline carbon dioxide & 3,188 & 2,640 & 1 & 1 & 3,188 & 2,640 \\
\hline water & 1,304 & 1,080 & 0.2 & 1 & 261 & 1,080 \\
\hline subtotals & 19,012 & 18,240 & & & 6,629 & 18,240 \\
\hline & & & & & total cost & 24,869 \\
\hline
\end{tabular}

10. (Redesign 1) The initial storage of the carbon dioxide that the waste processor would produce over a plant growth cycle is 132 moles/day *60 days $=7,920$ moles. The additional storage space for the carbon dioxide produced by the crew and not used by the plants in the 20 days after harvest and replanting is 548 moles per Table 2. The empty capacity to store a full inedible harvest is 5,400 moles more from Table 2.

11. (Redesign 2) Twice the amount of stored oxygen needed to support the crew during initial planting is 398 moles ${ }^{\star} 2=796$ moles, using Table 2 . How long can a waste processor failure last before the excess initial store of ten days food runs out before the next harvest? If the waste processor fails on or before day 21 , the stored carbon dioxide runs out after the fourteenth day of full canopy plant growth, day 35 of the plant cycle. Each day of edible growth with only the crew carbon dioxide, produces $(1 / 2) /(6 / 5)=5 / 12$ of the maximum edible biomass and loses 7/12. Each day of edible growth we produce $60 / 25$ of all the edible harvest, so we lose $(7 / 12)^{*}(60 / 25)=7 / 5$ days worth of food every day we have only crew carbon dioxide. We will exhaust our ten days food storage, if we have only crew carbon dioxide, in $10 /(7 / 5)=7.1$ days. 14 days stored carbon dioxide plus 7 days stored food $=21$, so we will be short of food if the waste processor failure lasts more than 21 days.

12. (Redesign 3) How much food is lost if the waste processor fails throughout the planting cycle? During the edible growth, only the crew supplies carbon dioxide, since the waste processor has failed and the stored carbon dioxide is exhausted. During the 25 days of edible growth, we receive from the crew 25 days ${ }^{*}(1 / 2)=$ 12.5 days average daily carbon dioxide use. We require 30 days average carbon dioxide use over the 25 day edible growth period for full edible production. We produce ( 12.5 days use $/ 30$ days use) ${ }^{\star} 60$ days' food $=25$ days' food and so are short 35 days' food. $60+35=95$ days' food. 95 days' food * 90 moles food $/$ day $=8,550$ moles food.

13. (Redesign 4) The carbon dioxide buffer holds enough carbon dioxide for a full plant growth cycle, allowing for the half supplied by crew metabolism, plus the initial amount generated by the crew while the plants are small. This is 132 moles/day * 60 days +548 moles (Table 2$)=8,468$ moles. The minimum 60-day supply of edible biomass is 5,400 moles (Table 2). The initial oxygen storage is twice the crew need during initial planting, $2{ }^{\star} 398$ moles, Table 2 . The oxygen buffer capacity is larger by the half of the oxygen that the plants produce over a plant growth cycle 192 moles/day *60 days $/ 2=5,760$ moles. This oxygen is normally used by the waste processor and would overflow if the buffer were not increased. 